\title{
¿Qué estimula la emoción en las audiencias? Un estudio de caso sobre persuasión, distorsión y emoción en las noticias*
}

\author{
César Augusto Tapias Hernández** \\ Recibido: 2019-02-02 • Enviado a pares: 2019-02-15 \\ Aprobado por pares: 2019-04-29 • Aceptado: 2019-05-20 \\ https://doi.org/10.22395/angr.v18n35a12
}

\begin{abstract}
Resumen
En este artículo se describe de qué manera un evento enmarcado en el género periodístico de la "entrevista" constituye una narrativa engañosa que, incluso después de ser rectificada, seguirá afectando a las audiencias convocadas emocional e ideológicamente. Se trata de un estudio de caso desarrollado a través de un análisis de contenido para explicar cómo emerge una noticia falsa en un noticiero de la televisión privada en Colombia a través de la introducción de frases falsas que, combinadas con el encuadre, las narrativas emocionales y las distorsiones, agudizan la polarización política y dejan ver cómo se insertan estas emociones en la narrativa noticiosa. Los resultados muestran que los sesgos de distorsión, no necesariamente partidistas, y las emociones alineadas con los principios ideológicos junto a las ganancias del mercado, son el caldo de cultivo para la gestación de las noticias falsas. El objetivo de este trabajo es mostrar de qué manera medios tradicionales como la televisión y sus estrategias de persuasión narrativa, proporcionan a sus audiencias, materiales (falsos) para la construcción (sesgada) de noticias (falsas), mientras emocionan al público, lo que genera beneficios políticos y económicos para el medio, el grupo económico del que hace parte el medio, y el candidato presidencial que el grupo respalda. El hallazgo más importante radica en que el sesgo emocional que procura el medio privado de información noticiosa estudiado no se agota en una explicación de su carácter partidista; en juego están las audiencias del mejor horario de la televisión colombiana, así como los beneficios económicos para un segmento del mercado publicitario.
\end{abstract}

Palabras clave: información; persuasión; emoción; medios de información; índice de audiencia.

* Este artículo presenta resultados de una investigación formativa sobre el origen de las noticias falsas para la clase doctoral Seminario Teórico II del segundo semestre del 2017, en la línea de investigación Estudios de Medios, Periodismo y Opinión Pública, del Doctorado en Comunicación de la Universidad de Norte (Colombia).

** Doctorando en Comunicación de la Universidad del Norte, Barranquilla (Colombia). Miembro del Grupo de Investigación en Comunicación, Cultura y Cambio Social PBX del Departamento de Comunicación Social de la Universidad del Norte. Correo electrónico: ctapiasa@uninorte.edu.co. Orcid: https://orcid.org/0000-0002-2555-7935 


\title{
Exploring the Origin of Fake News. A Case Study on Persuasion, Distortion and Emotion in the News
}

\begin{abstract}
This article describes how a deceptive event framed in the "interview" journalistic genre makes up a deceptive narrative that, even after being rectified, will continue to affect the audiences summoned emotionally and ideologically. It is a case study developed through a content analysis to explain how a fake news appears in a newscast of private television in Colombia, through the introduction of false phrases that, combined with the framing, emotional narratives and the distortions, sharpen the political polarization and reveal how are these emotions inserted in the news narrative. The results show us that the biases of distortion, not necessarily partisan, and the emotions aligned with the ideological principles together with the gains of the market, are the breeding ground for the gestation of false news. The objective of this paper is to show how traditional media, such as television and its strategies of narrative persuasion, provide their audiences, (fake) materials for the (skewed) construction of (fake) news, while exciting the public, which generates political and economic benefits for the news médium the economic group that it is part of, and the presidential candidate supported by the group. The most important finding is that the emotional bias sought by the private media of news information studied is not limited to an explanation of its partisan character; at stake are the audiences of the best schedule of Colombian television, and the economic benefits for a segment of the advertising market.
\end{abstract}

Keywords: information; persuasion; emotion; media; rating.

\section{O que estimula a emoção nas audiências? Um estudo de caso sobre persuasão, distorção e emoção nas notícias}

\section{Resumo}

Neste artigo descreve-se de que maneira um evento enquadrado no gênero jornalístico da "entrevista" constitui uma narrativa enganosa que, inclusive depois de ser retificada, continuará afetando as audiências convocadas emocional e ideologicamente. Trata-se de um estudo de caso desenvolvido a partir de uma análise de conteúdo para explicar como surge uma notícia falsa em um noticiário da televisão privada na Colômbia por meio da introdução de frases falsas que, combinadas com a abordagem, com as narrativas emocionais e com as distorções, agravam a polarização política e mostram como essas emoções se inserem na narrativa noticiosa. Os resultados mostram que os vieses de distorção, não necessariamente partidaristas, e as emoções alinhadas com os princípios ideológicos juntamente com os lucros do mercado são o substrato para a geração das notícias falsas. O objetivo deste trabalho é mostrar de que maneira os meios tradicionais como a televisão e suas estratégias de persuasão narrativa proporcionam a suas audiências material (falsos) para a construção (distorcida) de notícias (falsas), enquanto emocionam o público, o que gera benefícios políticos e econômicos para o meio, para o grupo econômico do qual o meio faz parte e para o candidato presidencial que o grupo respalda. A descoberta mais importante radica no fato de que o viés emocional que o meio privado de informação noticiosa estudado procura não se esgota em uma explicação de seu caráter partidarista; estão em jogo as audiências do melhor horário da televisão colombiana, assim como os benefícios econômicos para um segmento do mercado publicitário.

Palavras-chave: informação; persuasão; emoção; meios de informação; índice de audiência. 
Tener o no un final feliz depende de dónde decidas detener la historia.

(ORSON WeLLS)

\section{Introducción}

En la noche del 30 de octubre de 1938, un locutor de noticias anunciaba, en un informe que cumplía fielmente las convenciones de la radio de noticias, una invasión alienígena, con unas pocas advertencias que etiquetaban el contenido como ficción. Aunque Orson Wells, el actor que interpretaba el papel de locutor de noticias, había hecho una "admirable demostración" acerca del poder de la radio para excitar terrores, incitar odios, inflamar masas (Chen, 2017), el verdadero pánico fue el que produjeron los periódicos, que exageraron el temor de la gente por semanas, solo para advertir la necesidad de controlar al nuevo medio que era la radio, ya que se estaba convirtiéndo en la fuente dominante de noticias de última hora en los años treinta. Chen cita varios anuncios de prensa:

"Treinta hombres y mujeres se apresuraron a la estación de policía de la calle 123 del oeste, listos para evacuar", según el Times. Dos personas sufrieron ataques cardíacos por shock, informó el Washington Post. Un sujeto de Pittsburgh afirmó que apenas había impedido que su esposa se suicidara al tragar veneno. (Chen, 2017, p. 6)

En el 2016, casi noventa años después, los medios tradicionales siguen pidiendo control de los nuevos medios, internet en este caso. Para muchas personas, la victoria de Donald Trump en las elecciones presidenciales de Estados Unidos, ha sido una demostración de cómo internet se puede usar para lograr los fines que advertía Wells. El ascenso del magnate como presidente americano anuncia un cambio en el "régimen emocional" hacia lo que Wahl-Jorgensen (2018) llama "populismo enojado" que, encarnado por Trump, se basa en una retórica ampliamente atractiva a través de la expresión deliberada del enojo.

En Colombia, el triunfo del "No" al plebiscito por la paz en octubre del 2016 e puede leer de manera similar: en medio de una sucia campaña fundada en mentiras y exageraciones se buscaba "que la gente saliera a votar verraca", según lo comentó en una entrevista al diario La República Juan C. Vélez, gerente de la Campaña por el No en el plebiscito (La República, 2016). Las razones de la oposición a la refrendación del acuerdo de paz con las Fuerzas Armadas Revolucionarias de Colombia - Farc-Ep fueron características de una fuerte tendencia populista de derecha y excluyente, que criticó las propuestas de distribución y formalización de la tierra entre campesinos víctimas de la guerra, maldijo la expresión "enfoque de género y orientación sexual diversa" (Malagón, 2016), promovió su inconformidad por la justicia transicional (El Heraldo y Uninorte, 2017) y las sanciones restauradoras y, en general, logró introducir 
modificaciones al acuerdo original (Gobierno Nacional y FARC-EP, 2016) que limitaron más la ampliación de derechos y los controles políticos para garantizar la democracia y la justicia (Gómez Y Agudelo, 2016). Como lo hizo Trump, la oposición al acuerdo de paz en Colombia había convocado votantes, en gran parte porque identificó el atractivo de una nueva y más enojada forma de discurso político: la ira. Según Wahl-Jorgensen (2018), esta última es fundamental para entender el lugar de este populismo enojado como el régimen emocional de la era actual.

Hoy, la desinformación en línea, el discurso de odio y la propaganda malintencionada se ven como la primera línea de un recrudecimiento populista reaccionario que amenaza a la democracia. En este escenario, la ira aparece como un marco interpretativo viable para el discurso político y su desempeño, junto con las motivaciones de los actores políticos. Por ejemplo, en Filipinas, los partidarios en línea del presidente Duterte han atacado a grupos críticos de sus políticas como su campaña contra las drogas que, durante su primer año en el cargo, resultó en el asesinato de al menos 7.000 usuarios y vendedores de drogas (Human Rights Watch, 2017). Un informe de investigación de Rappler, una red de noticias sociales en la que las historias inspiran el compromiso de la comunidad y las acciones impulsadas digitalmente para el cambio social (Rappler, s. f.), mostró cómo los seguidores de Duterte usaban cuentas falsas y bots para "ignorar la verdad y manipular las emociones" gracias al algoritmo de Facebook (véase Ressa, 2016).

Como veremos, las estrategias desplegadas en el 2016 para impulsar tanto la popularidad de Duterte en Filipinas (Labiste, 2017) como el triunfo de Trump en Estados Unidos. (Wahl-Jorgensen, 2018), y del No al Acuerdo de Paz, continúan hasta nuestros días: las noticias falsas, su difusión y la relación que las audiencias tienen con los medios de comunicación tradicionales representan las tensiones más importantes en el debate público en el mundo entero, tanto más frente a procesos electorales como los desarrollados en Colombia después de los acuerdos de paz entre el Estado colombiano y las FARC-EP.

Los textos de las redes sociales también pueden enmascarar o hacer incomprensibles los mismos hechos necesarios para pensar críticamente en una cultura digital que tolera la falsedad en sus diversos disfraces (véase Alvermann, 2017), a la manera de los argumentos falaces o erísticos descritos por Aristóteles hace 2.500 años como "argumentos inválidos que tienen la apariencia de ser válidos o, que no prueban nada, pero parecen probarlo todo" (Beuchot, 1997, p. 9). Pero, si bien las empresas de tecnología y redes sociales, como Google, Facebook y Twitter, tienen una responsabilidad directa a la hora de propagar contenidos malintencionados, ideologizados y que faltan a la verdad, también existe la posibilidad de crearlos y difundirlos a través de medios de comunicación tradicionales, como la televisión para nuestro caso, al alinearse con 
intereses políticos no solo de carácter partidista sino de las ganancias que les genera el mercado de clics (Bolton y Yaxley, 2017).

De esta forma, considerando la emoción como un factor decisivo en la política mediatizada, el objetivo de este artículo es identificar cómo se insertan estas emociones en la narrativa de las noticias o mejor aún, identificar cómo estimula el medio la emoción en las audiencias y la relación de este proceso con las falsas declaraciones de políticos, para demostrar no solo que la ira es un recurso de oportunistas políticos, sino que el régimen de la emoción al que asistimos en la construcción de noticias propicia informes tendenciosos o engañosos, constituidos por modelos de persuasión en los que la necesidad de la cognición como disposición motivacional para el procesamiento de los mensajes es mínima, con lo que se afecta de forma negativa la opinión política de manera emotiva; mientras que de manera positiva se afecta a los políticos y grupos económicos defensores del libre mercado.

Como veremos, la anterior es una situación complicada ya que los medios, como lo dicen Konijn, Van der Molen y Van Nes (2009, p. 312), "requieren que las personas realicen juicios cada vez más sofisticados para determinar qué es real". En ese contexto retomo la pregunta de Enguix (2017) sobre cuáles son las funciones políticas e informativas que las empresas de noticias, de tecnología y redes sociales, desempeñan en el régimen emocional de la era actual, y cuál es su posible interferencia con el papel de los medios de información como actores políticos.

Este ejercicio de investigación es un estudio experimental que pretende evaluar la relación entre el régimen de la emotividad en las narraciones noticiosas y la emergencia de noticias falsas. El objeto de estudio que se somete al análisis es una narrativa noticiosa presentada como una entrevista en un noticiero de televisión, sobre el que se cuestiona la introducción de declaraciones falsas. Las premisas teóricas de esta investigación son la función de encuadramiento en el género periodístico de la entrevista; la persuasión narrativa que enmascara la manipulación emocional del medio noticioso para con sus audiencias, y la operación discursiva que termina por favorecer una práctica periodística sesgada. La metodología para el desarrollo del ejercicio es cuasi-etnográfica, ya que se trata de un diseño que incorpora un corto período de observación de campo a fin de aportar datos contextuales para lo que es, en esencia, un análisis de muestras o un estudio experimental (véanse Ginssburg, Meyenn \& Miller, 1980) que, aun cuando emplea conceptos y métodos etnográficos tradicionales, y los combina con otras técnicas y marcos teóricos, no utiliza los marcos interpretativos, conceptuales y teóricos de la antropología cultural.

La estructura argumental del artículo nos ubica primero el contexto teórico de las premisas mencionadas. Luego, se expone el aparato metodológico que combina el estudio de caso con el análisis de contenido bajo la perspectiva cuasi-etnográfica 
nombrada. Posteriormente se comparte el análisis con que se logran resultados, entre los que destaca que el sesgo emocional procurado por el noticiero de televisión no es solo partidista — sin querer decir que la artimaña mediática que construye no quería favorecer al candidato- se trató principalmente de un sesgo por distorsión de la información que favorecía al noticiero, a los comerciantes que pautaron en el espacio y al canal que legitimó su dominación del índice de audiencia en ese horario.

\section{Revisión de literatura}

En este apartado se recogen los aportes teóricos y conceptuales que nos permitirán explorar la compleja relación en la que se gestan noticias falsas en un noticiero de la televisión privada colombiana. En primer lugar, se hace referencia a la teoría del framing, en particular, la función de encuadramiento de algunos géneros periodísticos; seguidamente, se recogen apuntes sobre la persuasión narrativa para considerar que el núcleo del asunto tal vez esté dentro de la narración periodística y no en las etiquetas; y en tercer lugar, se destaca la manipulación emocional como una operación discursiva a la que favorecen ciertas prácticas periodísticas sesgadas por la filiación partidista o el mercado.

\section{Teoría del framing y los encuadres}

La definición de noticias falsas de Allcott y Gentzkow (2017) descarta como tales a errores de informes involuntarios, rumores que no se originan en un artículo periodístico en particular, teorías de conspiración, contenidos satíricos con poca probabilidad de malinterpretarse como reales; declaraciones falsas de políticos e informes tendenciosos o engañosos, pero no completamente falsos. En el lenguaje de Gentzkow, Shapiro y Stone (2014), las noticias falsas son un tipo de "distorsión" que difunde un acontecimiento aparentemente veraz, pero de una forma débilmente informativa. La pregunta que surge es entonces, ¿cómo se pueden distinguir las noticias débilmente elaboradas de otras más complejas? Según Iyengar y Kinder (1987, citados por Humanes, 2001), existen dos formatos de noticias: episódicas, como se conocen las noticias centradas en eventos específicos o casos particulares, y cuya cobertura se orienta hacia los acontecimientos; y temáticas, cuya cobertura se orienta hacia el contexto y la explicación. Este último formato requiere entrevistas con expertos en la materia, mientras que el primero excluye tales fuentes. Esto permite diferenciar, más que dos tipos noticias, dos modos de framing, o encuadre; se trata de dos formas de encuadrar las noticias que tienen efectos en el procesamiento de la información. Esta labor es similar a la función de los paratextos, que según Genete (1987, citado por Appel y Maleckar, 2012), identifican o etiquetan los géneros periodísticos de la entrevista o el reportaje, entre otros. 
El sentido común lleva a esperar que las indicaciones de género (por ejemplo, documentales o telenovelas) puedan ayudar al espectador a evaluar la realidad del contenido de un programa (Konijn et al., 2009). Hay trabajos -recientes, incluso- que sugieren que la información paratextual puede servir como una variable mediadora que atrae actividades de elaboración, debido a su papel como indicador de fiabilidad (según Petty y Wegener, 1998, citados por Appel y Maleckar, 2012). Pero, aunque la investigación de Green y Brock (2000) había mostrado que las historias tienen poder persuasivo independientemente de los paratextos, Green y Donahue (2009) sugirieron que las señales extratextuales pueden influir en los participantes para procesar una historia de manera diferente: aquellos que reciben una historia etiquetada como ficción podrían estar preparados para ser transportados más profundamente al mundo de la historia narrada. Así, las etiquetas de la historia influyen en el transporte, pero parece que, de todos modos, dar esa información, a sabiendas de que es falsa, de alguna manera afecta los juicios y el comportamiento de las audiencias (Appel y Maleckar, 2012).

\section{Persuasión narrativa}

De modo específico, Appel ha ampliado sus investigaciones (Appel y Richter, 2010; Appel y Maleckar, 2012) para examinar la influencia de la necesidad de afecto en la persuasión narrativa; y ha considerado investigar la influencia de introducir una historia como ficción o falsa, ya que esto involucra la sensación de ser transportados al mundo narrativo del evento noticioso. Junto a Maleckar y Richter, este autor consideró el poder persuasivo de las narraciones atribuido a un estado experiencial llamado transportación o, translación, desarrollado por Green y Brock (2000), quienes proponen la metáfora de que los receptores de una narración emprenden un viaje mental al mundo de las historias relatadas. Este traslado al mundo narrativo se caracteriza por una "combinación integradora de atención, imágenes y sentimientos o emociones, enfocadas en eventos de la historia" como lo plantearon después Green y Donahue (2009, p. 241). Se trata de la experiencia holística de ser absorbido por una historia que se superpone a otros conceptos que implican la inmersión en un mundo de historias más amplio. La idea de que esta transportación es un mecanismo general que subyace a la persuasión a través de narrativas ha recibido un apoyo empírico consistente: cuantos más destinatarios fueron transportados en la narración, más apoyaron las creencias consistentes en historias (Appel y Richter, 2010).

El asunto problemático aquí ilustrado, es que este tipo de inmersión en la historia no implica un examen esforzado o la elaboración de la información en la historia. La activación de experiencias y conocimientos previos se suele limitar a los recordatorios basados en historias similares, que tienden a ser congruentes con la historia central y contribuyen a un cambio de creencias coherentes con la historia, en lugar de la generación de contraargumentos. Los resultados de los experimentos realizados 
por Green y Brock (2000, p. 704) indicaron que "la correlación entre la necesidad de cognición y el transporte era pequeña e insignificante". Estos hallazgos proporcionan material para considerar que la persuasión narrativa de las noticias televisivas requiere más emoción y menos razonamiento. Mientras que el procesamiento y los efectos de las historias y otros mensajes basados en el afecto parecen ser independientes de la necesidad de la cognición; los estudios que midieron las diferencias individuales en la necesidad del afecto mostraron resultados más prometedores: Maio y Esses (2001, p. 585), por ejemplo, introdujeron la necesidad del afecto como la "motivación general de las personas para acercarse o evitar situaciones y actividades que inducen emociones para ellos y para los demás".

Con lo anterior, los periodistas logran, desde un régimen emocional, conectar con comunidades necesitadas de afecto más que de argumentos o ideas: "se supone que los participantes con una fuerte necesidad de afecto son particularmente sensibles a los estímulos, es decir, abordar las emociones facilitaría la experiencia de ser transportado al mundo mental de la narración" (Appel y Richter, 2010, p. 101). A partir de esto, los autores establecen la necesidad de la cognición como moderadora de la manipulación paratextual, mientras que la necesidad de afecto modera el efecto persuasivo del texto mismo. Como vemos, aquí lo central es la emoción. La respuesta emocional de los espectadores a los eventos que despiertan sus emociones puede alertar al sistema humano y desencadenar las tendencias de acción para luchar o huir. En este contexto, cuanto mayor es la necesidad de afecto de un individuo, mayor es el impacto persuasivo de una historia (Appel y Maleck, 2012).

\section{Manipulación emocional}

Varios estudios han demostrado que los sesgos en el procesamiento de la información se producen debido a las emociones experimentadas por los espectadores al ver los materiales audiovisuales; las personas incluso adoptan las emociones que se retratan en la televisión, muestran empatía por los personajes, se sumergen en la narrativa, o pasan por otros procesos afectivos. Por ejemplo,

[...] se encontró que el estado emocional de los espectadores motivó el procesamiento selectivo de información (Forgas, 1995), para enmarcar la información presentada posteriormente (Nabi, 2003), para llevar a errores de recuerdo (Brosius, 1993; A. Lang, 2000), para favorecer el material emocional en el recuerdo (Zillmann, Knobloch, y Hong-sik, 2001), y para influir en los errores de procesamiento de la información al creer que la ficción es real (Prentice y Gerrig, 1999). Estos hallazgos sugieren que los espectadores emocionales pueden percibir mensajes mediados de manera diferente que los espectadores no emocionales. (Konijn et al., 2009, p. 313)

Hay una definición de manipulación que resulta útil para este contexto: Romano (2011) la entiende como "el empleo deliberado del lenguaje para la confusión de las 
conciencias y la ocultación de la realidad" (p. 7). Esta manipulación emocional utiliza técnicas narrativas a través de aspectos sentimentales como la música, la prosodia, formas de lenguaje no verbal, luminosidad y colores, entre otros. En contraposición a la manipulación se concibe la "información" como elaboración, configuración, formación, proceso de explicación y aclaración (Romano, 2012, p. 26).

\section{Sesgo por distorsión}

El modelo de Kepplinger asume que los periodistas -en especial cuando tratan asuntos políticos, problemas sociales y conflictos o crisis- informan sobre acontecimientos no solo por su importancia natural, sino por su carácter instrumental para conseguir ciertos objetivos (Humanes, 2001). Cada empresa informativa tiene una estrategia de informes que mapea desde las señales que recibe hasta las noticias que publica. Estas empresas pueden decidir informar las señales con sinceridad o, de modo alternativo, agregar un sesgo a los informes (Allcott y Gentzkow, 2017). De hecho, los diferentes medios de comunicación seleccionan, discuten y presentan los hechos de manera diferente, y lo hacen de maneras que tienden a favorecer sistemáticamente a un lado del espectro político o el otro. Estas diferencias pueden tener grandes efectos en el comportamiento de los votantes y, por lo tanto, en los resultados políticos.

Las preocupaciones sobre el sesgo han sido un motor central de la regulación de los medios (véanse Gentzkow, Shapiro y Stone, 2014). Por lo tanto, comprender las fuerzas económicas que determinan el contenido de los medios resulta de gran importancia para estos tres autores, ya que puede explicar por qué los medios pueden ocultar información de forma estratégica; ello se conoce como sesgo de distorsión. Los consumidores aún pueden ser manipulados por sesgo, ya que cuando la información política es mala (desde la perspectiva de la empresa) y no se informa, los consumidores no pueden saber si esto se debe a la no divulgación o si la información no está disponible. En este nivel de distorsión estaría cualquier medio noticioso que ajusta las noticias pensando en el consumidor, en razón de que priman las ganancias sobre el servicio púbico de la información'.

Todo lo anterior sirve para tratar de explicar de forma teórica las razones por las que un contenido televisivo de carácter noticioso en horario prime time -con mayor audiencia y publicidad más costosa- puede constituir un campo de cultivo para las noticias falsas generadas por las empresas mediáticas. Pero antes, es preciso explicar la metodología con la cual se pretende aquí que la evidencia empírica dialogue con estos desarrollos teóricos.

Véase el análisis de las noticias falsas en elecciones presidenciales de Estados Unidos de 2016 realizado por Muñoz (2017). 


\section{Metodología}

La investigación cualitativa permite múltiples interpretaciones de la realidad. Schwartzman, (1993, p. 4, citado por Reyes, 1999, p. 77) caracterizó las diversas tradiciones del enfoque cualitativo en seis orientaciones: etiología humana, psicología ecológica, etnografía holística, antropología cognitiva, etnografía de la comunicación e interaccionismo simbólico. La orientación más útil para la investigación de este artículo es la etnografía de la comunicación, que se centra en datos sobre interacciones verbales y no verbales, que descansan en la observación de los participantes y la grabación audiovisual de dichas interacciones para un visionado crítico posterior (Reyes, 1999, p. 78).

Entre las técnicas más adecuadas para la orientación de este enfoque cualitativo, están la observación participante, la entrevista en profundidad, el grupo focal y el estudio de caso. Esta última técnica resulta apropiada para el ejercicio cuasietnográfico que propone esta investigación, en tanto constituye un examen intensivo a una entidad (Reyes, 1999, p. 83). Se trata de una técnica que permite la recolección e interpretación detallada de toda la información disponible sobre un individuo, institución, empresa, movimiento social, actividad o proceso. En este sentido, el estudio de caso toma al objeto entrevista/noticia televisiva como unidad, como universo de investigación o, lo que es igual, como estudio de caso único (Editorial Santillana, 2005, p. 232).

Los estudios de caso se pueden clasificar en dos tipos: uno que deriva conclusiones a partir de un número limitado de casos; y otro que intenta llegar a conclusiones a partir de un solo caso. Para esta investigación sobre la inserción de las emociones en una noticia, por partir de un solo caso, el estudio es además situacional, o estudio de caso simple que responde a un diseño holístico; es decir que el estudio se desarrolla sobre un solo objeto, proceso o movimiento (Yin 1984, citado por Reyes, 1999).

El caso analizado es del tipo situación crítica, por ser el estudio de caso que examina una situación singular, de interés único, que serviría como prueba crítica de una aseveración acerca de un programa, proyecto, problema o estrategia de trabajo. En este caso, una prueba crítica sobre cómo y con qué propósitos un noticiero de la televisión privada colombiana estimula la emoción de su audiencia a través de la difusión de argumentos falaces.

\section{Técnicas, instrumentos y procesos de observación}

Si bien el estudio de caso es válido como una técnica para entender o tomar decisiones con relación a un objeto de estudio, también funciona como instrumento de obser- 
vación dentro de la investigación documental en tanto unidad específica (Caramon y Martínez, 2004). En Lexipedia se define esta unidad específica o caso de la siguiente manera: "(...) (Del latín casus) m. Suceso, acontecimiento//casualidad// lance ocasión// Asunto de que se trata o que se consulta // En medicina paciente con especie patológica individualizada// En las epidemias" (Lexipedia, 2002, p. 390).

La investigación con casos identifica 3 etapas:

1) Planeación: en esta etapa se desarrolló la planeación del estudio de caso que debía derivar en el protocolo de investigación.

2) Ejecución: durante esta etapa se hizo levantamiento de la información según lo planificado en la etapa 1, y se obtuvo como resultado la base de datos del estudio de caso.

3) Análisis y presentación de resultados: se presentó la información, se analizó y se obtuvo el reporte del estudio de caso y el caso de estudio.

Sin embargo, si el estudio de caso se asume como instrumento de observación en perspectiva etnográfica, como se lo propone este ejercicio, se hace necesario el uso de otra(s) técnica(s) de apoyo, o de control. Para este caso, será el análisis del discurso. Así, las observaciones detalladas del caso permitirán estudiar variados aspectos del objeto de análisis, entre ellos los cuatro ítems detallados en la revisión de literatura: encuadre, persuasión narrativa, manipulación emocional y sesgo por distorsión.

Usaremos aquí el enfoque semántico y pragmático del análisis del discurso, que ve al discurso como un hecho comunicativo y resultado de un conjunto de operaciones cognitivas (Molero de Cabeza, 2003). Esto exige relacionar las propiedades del discurso con aspectos del contexto -interaccional o estructural- en que el discurso se ha producido. Según la Retórica general (Ibáñez ,1978, citado por Jociles Rubio, 2005), un análisis del discurso se desarrolla en tres niveles:

1) Nuclear: consiste en un análisis de las propiedades internas del discurso, es decir, de elementos nucleares y de las estructuras elementales del material discursivo.

2) Autónomo: aquí, el material discursivo se descompone en diferentes discursos o textos que se puedan relacionar con distintos aspectos de clase, edad, género, subcultura o, por ejemplo, credo político y lograr un análisis de la relación de las propiedades internas del discurso con las propiedades de quienes lo enuncian o lo reciben.

3) Sýnnomo: en este nivel se recupera la unidad del material discursivo, para analizar e interpretar la relación dialéctica entre los discursos, cómo los discursos se constituyen mutuamente entre sí, y la relación entre esos discursos y el contexto sociocultural del que forman parte. 
El potencial heurístico, o las posibilidades de creación y descubrimiento de esta combinación de técnicas, está centrado en la relación entre el problema de investigación y la unidad de análisis, es decir, cómo un noticiero estimula emocionalmente a las audiencias y los formatos noticiosos que utiliza como escenario para la estimulación emocional.

La unidad de análisis es una unidad etnográfica en pequeña escala, ya que se estudia una unidad mínima: la actividad o el proceso de producir noticias que estimulen la emoción, el problema, o cómo se insertan las emociones y declaraciones falsas en el contexto de las elecciones presidenciales de Colombia.

\section{Protocolo, o cómo llevar a cabo registros}

- Fuentes primarias: observación y toma de notas sobre las interacciones verbales, no verbales y gráficas en una entrevista a un candidato presidencial y su entrevistador, en un noticiero de televisión privada en horario triple A, o prime time, para un visionado crítico posterior.

- Fuentes secundarias: se consultó una encuesta de favorabilidad electoral a la población adulta de género masculino y femenino aplicada por los días de la transmisión televisiva en cuestión (Semana, 2018). Otros datos relevantes para este trabajo, que están relacionados con el problema de investigación, corresponden a información en redes sociales.

\section{Ejecución}

Se procedió a realizar un visionado crítico de la entrevista televisada, que se encuentra disponible en el canal de YouTube. Se tomaron notas de observación y análisis del material, que se segmentó en un grupo de seis variables en función de las cuatro premisas teóricas. Asimismo, se consignaron los datos en una matriz de análisis y algunos de ellos se contrastaron con otras fuentes, específicamente por quienes produjeron la principal prueba, no contrastada en su momento por el medio noticioso.

Tabla 1. Matriz para el análisis de las categorías

\begin{tabular}{|c|c|c|c|c|}
\hline $\begin{array}{l}\text { Categoría } \\
\text { Unidad }\end{array}$ & Encuadre & Persuasión narrativa & $\begin{array}{c}\text { Manipulación } \\
\text { emocional }\end{array}$ & Sesgo por distorsión \\
\hline $\begin{array}{l}\text { Entrevistador/ } \\
\text { presentadores }\end{array}$ & Entrevista & Contra la JEP & $\begin{array}{l}\text { "El exvicepresidente } \\
\text { lanzó advertencias } \\
\text { que levantarán am- } \\
\text { polla [...]" }\end{array}$ & $\begin{array}{l}\text { Como veremos, la } \\
\text { realidad registrada } \\
\text { y transmitida en el } \\
\text { noticiero no acon- } \\
\text { teció en Saravena } \\
\text { sino en otro lugar. }\end{array}$ \\
\hline
\end{tabular}




\begin{tabular}{|c|c|c|c|c|}
\hline $\begin{array}{l}\text { Categoría } \\
\text { Unidad }\end{array}$ & Encuadre & Persuasión narrativa & $\begin{array}{c}\text { Manipulación } \\
\text { emocional }\end{array}$ & Sesgo por distorsión \\
\hline Entrevistado & $\begin{array}{l}\text { "Le tengo un } \\
\text { videíto [...]" }\end{array}$ & $\begin{array}{l}\text { "Yo considero que } \\
\text { el tema de la jep } \\
\text { [Justicia Especial } \\
\text { para la Paz] hace } \\
\text { parte de una estra- } \\
\text { tegia política". }\end{array}$ & $\begin{array}{l}\text { "O qué otro partido } \\
\text { político va a recibir } \\
30 \text { emisoras, varios } \\
\text { senadores y repre- } \\
\text { sentantes por dere } \\
\text { cho propio [...]" }\end{array}$ & $\begin{array}{l}\text { "iEl mismo mode- } \\
\text { lo que vemos en } \\
\text { Venezuela!" }\end{array}$ \\
\hline $\begin{array}{l}\text { Comunicación } \\
\text { verbal }\end{array}$ & $\begin{array}{l}\text { "¿Tiene prue- } \\
\text { bas?", pregunta } \\
\text { el entrevistador } \\
\text { al entrevistado } \\
\text { que hace la de- } \\
\text { nuncia. }\end{array}$ & $\begin{array}{l}\text { Le tengo un videí- } \\
\text { to, ¿̇lo miramos? }\end{array}$ & $\begin{array}{l}\text { Preguntas del entre- } \\
\text { vistado al entrevis- } \\
\text { tador: "¿a quién le } \\
\text { dieron } 30 \text { emisoras?, } \\
\text { ¿a quién le dieron } \\
\text { curules en el Con- } \\
\text { greso?" }\end{array}$ & $\begin{array}{l}\text { [...] en Saravena } \\
\text { [municipio arau- } \\
\text { cano afectado por } \\
\text { las guerrillas]. }\end{array}$ \\
\hline $\begin{array}{l}\text { Comunicación } \\
\text { no verbal }\end{array}$ & $\begin{array}{l}\text { Asombro } \\
\text { de parte del } \\
\text { entrevistador }\end{array}$ & $\begin{array}{l}\text { Manoteos del en- } \\
\text { trevistador, mira- } \\
\text { das que evitan la } \\
\text { cámara lo la mira- } \\
\text { da de los especta- } \\
\text { dores]. }\end{array}$ & $\begin{array}{l}\text { Asombro de parte } \\
\text { del entrevistador. }\end{array}$ & $\begin{array}{l}\text { "[...] todo esto es } \\
\text { muy grave", dice el } \\
\text { entrevistador. }\end{array}$ \\
\hline $\begin{array}{l}\text { Comunicación } \\
\text { gráfica }\end{array}$ & $\begin{array}{l}\text { Entrevista } \\
\text { exclusiva }\end{array}$ & $\begin{array}{l}\text { Varios magistrados } \\
\text { fueron apoderados } \\
\text { de los guerrilleros. }\end{array}$ & $\begin{array}{l}\text { Nos quitaron el juez } \\
\text { natural a } 48 \text { millones } \\
\text { de colombianos. }\end{array}$ & $\begin{array}{l}\text { Cubanos están en } \\
\text { zonas de reserva } \\
\text { campesina. }\end{array}$ \\
\hline
\end{tabular}

Fuente: elaboración propia.

\section{Análisis}

\section{Examinar unos hechos lingüísticos y de comunicación}

Los datos empíricos que sirven para discutir desde la realidad mediática y política son segmentos de la entrevista central del noticiero de televisión colombiano Caracol Noticias, emitido del 14 de octubre del 2017 en horario prime time (7 - 11 p.m.), con el que se abrió la campaña electoral por la Presidencia de la República para el cuatrienio 2018-2022, y en el que se entrevistó al candidato "más opcionado" por las encuestas del momento.

Este noticiero pertenece a la compañía colombiana Caracol Televisión, que en la actualidad es uno de los negocios centrales del Grupo Valorem, propiedad del empresario Alejandro Santo Domingo Dávila, junto con los medios de información y entretenimiento Blu Radio, La Kalle, El Espectador y Cine Colombia, y las revistas Cromos, Shock y Vea.

La compañía comenzó a gestarse en 1954, cuando adquirió la concesión de determinados espacios de programación televisiva pública con fines de explotación 
comercial; pero solo hasta 1998 inició transmisiones como canal privado de televisión. Ya en el 2008 Caracol Televisión y sus filiales Caracol TV América Corp. y Caracol Televisión Inc., constituyeron una de las cinco compañías productoras y distribuidoras más grandes de América Latina, con presencia en más de cincuenta países del mundo. En actualidad se le critica, junto a su competidor RCN Noticias, por usar un "formato 10 por 10", que no es otra cosa que diez minutos de noticias por diez minutos de comerciales. Para el 2017, muchos críticos sospechaban que el canal tenía sus preferencias políticas para la Presidencia de la República, contexto en el que se analiza aquí su bloque de entrevistas.

La entrevista central para este artículo era anunciada así por las presentadoras del noticiero: más que etiquetar o encuadrar el tipo de formato que mediaba el contenido informativo, se creaban las condiciones persuasivas para el viaje narrativo que proporcionaba la narración de la noticia de Noticias Caracol (2017) hacia la realidad política nacional de Colombia, y sobre los que correspondería tomar una posición (tabla 2).

Tras el protocolo paratextual, la entrevista inicia con la presentación del candidato dentro del segmento y la reivindicación de la alerta mediática y política que significa que un exfuncionario, otrora impedido, emita críticas específicas contra al gobierno del que formó parte y en particular, contra los acuerdos alcanzados con la guerrilla de las Farc-Ep, que como entenderemos, representa una situación amenazante para un potente caudal electoral de, como mínimo, seis millones de votos que se oponen a la paz.

Tabla 2. Notas y transcripción del visionado

\begin{tabular}{ll}
\hline Presentadora & "Vargas Lleras se lanzó al ruedo e hizo muy \\
uno: & duros reparos al proceso de implementación \\
& con las FARC, a quienes acusó de montar una \\
& estrategia ilícita con la izquierda radical y tres \\
& candidatos presidenciales." \\
\hline Presentadora & "El exvicepresidente lanzó advertencias que \\
dos: & levantarán ampolla, por ejemplo, que las \\
& FARC quieren someter a la justicia transi- \\
& cional al expresidente Álvaro Uribe Vélez, \\
& también pidió que los militares implicados \\
& en falsos positivos que vayan a la JEP tengan \\
& los mismos beneficios de los exguerrilleros."
\end{tabular}

Presentadora uno:

"Esta es la primera parte de una explosiva entrevista que Germán Vargas Lleras dio a

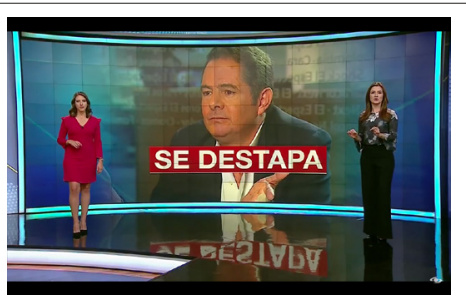

Fuente: Noticias Caracol, 2017. nuestro director Juan Roberto Vargas. Esto es exclusivo de Noticias Caracol".

Fuente: elaboración propia. 
Tabla 3. Notas y transcripción del visionado

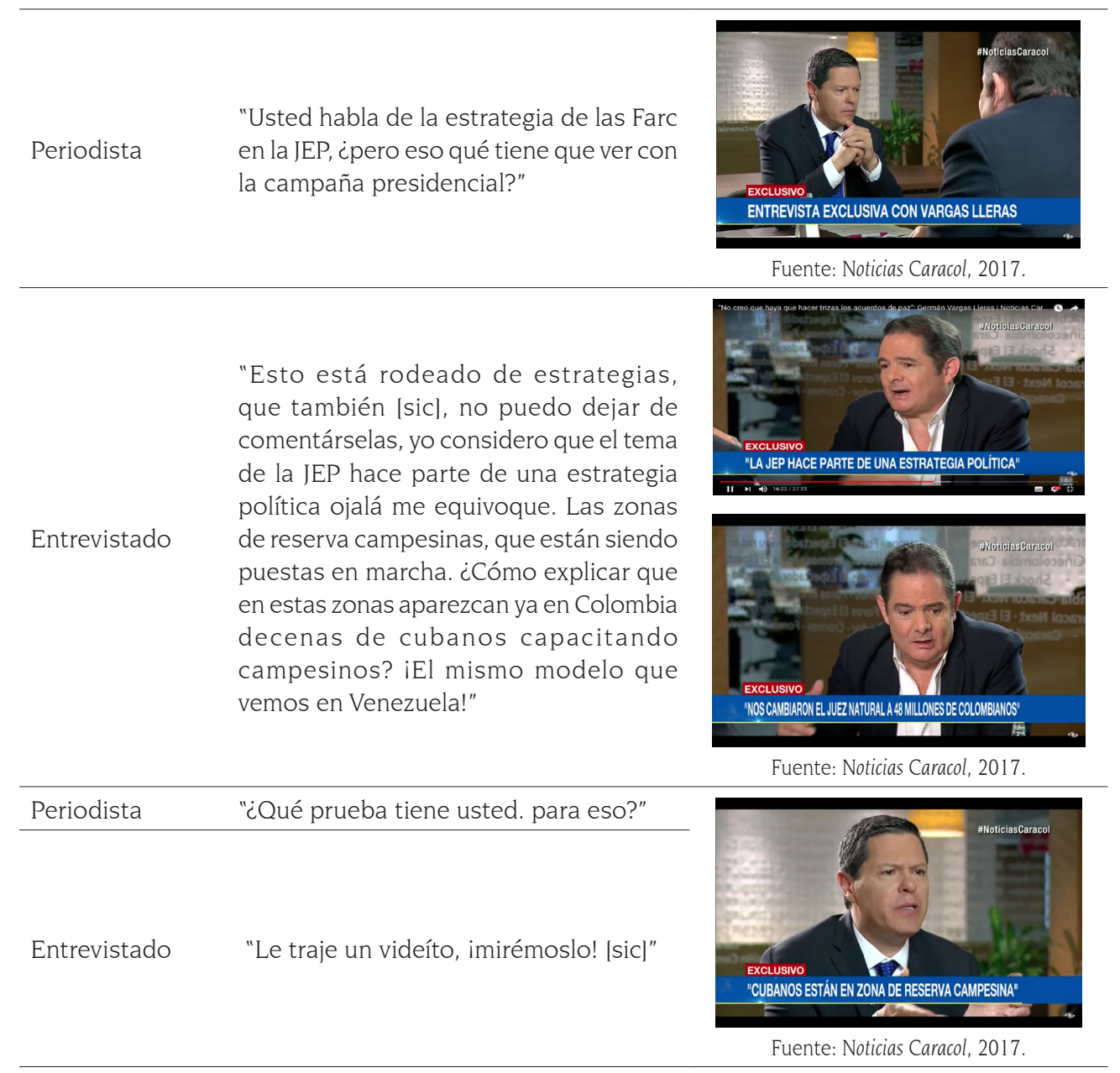

Fuente: elaboración propia.

De inmediato, se emite un material audiovisual aportado por la fuente, de una duración de 17 segundos, durante los cuales se escucha y ve a una mujer que habla de los beneficios de la unidad campesina con acento cubano. Entre planos alternados de una reunión de varias personas y la mujer, el video ostenta títulos superpuestos: en la parte superior izquierda, dice (en mayúsculas) "VIDEO CAMPAÑA VARGAS LLERAS"; en la superior derecha, el intertítulo "Noticias Caracol"; en la inferior derecha, el logosímbolo del Canal Caracol, y una banda inferior que atraviesa la imagen dice: "Cubanos adiestrando campesinos en Saravena, Arauca". Cuando se regresa al estudio donde se realiza la entrevista a la fuente, el periodista, "sorprendido", pregunta lo expuesto en la tabla 4. 
Tabla 4. Notas y transcripción del visionado

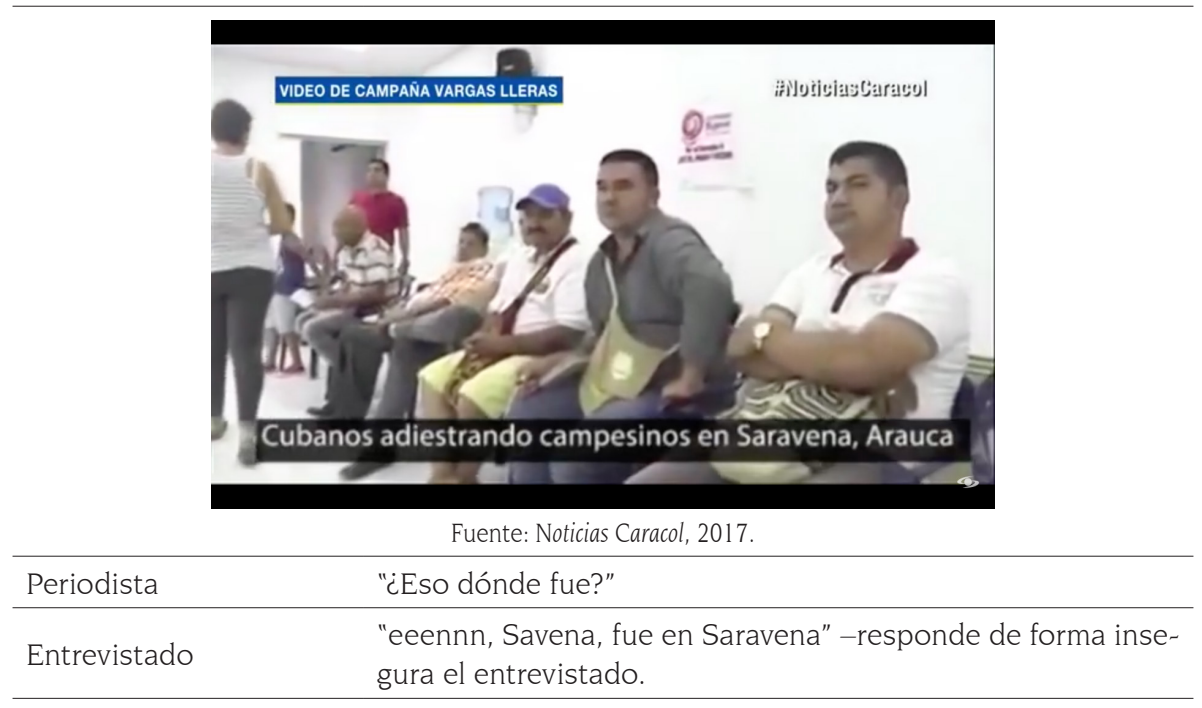

Fuente: elaboración propia.

Sorprende la pregunta del periodista, que parecía no saber lo que compartía la fuente; ello pone en evidencia que quizás no contrastó la información. El entrevistado, por su parte, deja ver con todas las señales de su rostro que intenta no develar un engaño, esforzándose para hablar sin mirar de forma contundente al entrevistador o a la cámara; solo alza la voz para insistir "fue en Saravena", un municipio del departamento de Arauca, limítrofe con Venezuela -en donde, si se busca con atención en documentos oficiales y la prensa, no hay ni siquiera proyectada una zona de reserva campesina-.

Como se verá más adelante, la realidad registrada y transmitida en el noticiero no aconteció en Saravena sino en otro lugar, conocido como Sarare. Así entonces, se entiende pronto el tono de la contienda electoral en Colombia: con aquiescencia de los medios masivos de comunicación, una campaña marcada por engaños, o al menos por una cierta falta de ética periodística, en tanto que no se verifica la información que se emite, ni se la contextualiza, con lo que alcanza hasta para considerar la imagen que el noticiero tiene de su audiencia: esto es, una masa emocional fácil de confundir, gracias a su reputación como medio de comunicación y al poder de la retórica del odio que logra construir el entrevistado. "O qué otro partido político va a recibir 30 emisoras, varios senadores y representantes por derecho propio [...]" - dice en el candidato en otro aparte del segmento.

Por supuesto, el material aportado era falso, o "erróneamente" descrito. Las reacciones en las redes sociales -nunca dentro de emisiones posteriores del noticiero o de medios aliados en prensa y radio- no se hicieron esperar: 
Los habitantes de Saravena consideramos que German Vargas Lleras, nos estigmatiza y nos utiliza para ganar caudal electoral" - dijo tajantemente Diego Fernando Vera, personero del municipio en entrevista radial con Meridiano 70, una emisora comunitaria en Arauca ${ }^{2}$ - Saravena no es zona de reserva campesina -explicó-; utilizan ese nombre para desdibujar un contexto social y estigmatizar a la población del Sarare, y dejar a la comunidad del departamento en un sinsabor ante la opinión pública, señalándonos de estar preparándonos para gobernar desde un sistema político similar al de Venezuela. (Meridiano 70, 2017)

Por su parte, el Movimiento Político de Masas Social y Popular del Centro Oriente de Colombia, citado en el informe de Meridiano 70, se refirió a la entrevista del candidato presidencial German Vargas Lleras:

[...] Basa sus acusaciones en un video elaborado por la Corporación Trochando Sin Fronteras, medio de comunicación popular de nuestro movimiento, al respecto de una visita hecha por compañeros y compañeras de la Asociación Nacional de Campesinos Pequeños y del Centro de Memoria Martin Luther King de Cuba, a nuestra región en el marco del relacionamiento internacional. (Meridiano 70, 2017)

Sin lugar a dudas, la presentación del video que registraba un encuentro público de comunidades y organizaciones sociales, confundiéndolo o haciéndolo ver como una estrategia de las FARC, es una forma de satanizar y criminalizar las iniciativas populares, de ocultar la verdadera situación del país, y de generar terror en los pobladores y aprovecharlos como caudal electoral en las próximas contiendas, sin dejar de mencionar que la emisión del noticiero genera beneficios económicos para el canal, debido a la pauta publicitaria en un horario premier. No en vano el movimiento político consultado en el informe de prensa comunitaria le exigió al medio masivo de comunicación (Canal Caracol), rectificar esa información:

[...] porque se genera confusión y desinformación en el pueblo colombiano y aumenta los riesgos para la vida, integridad y libertad de los dirigentes sociales y defensores de derechos humanos que participaron en el encuentro de campesino a campesino y que aparecen en el video usado malintencionadamente por el candidato Germán Vargas Lleras y ese medio. (Meridiano 70, 2017)

Resulta interesante la solicitud de rectificación al medio puesto que, cuando menos en la percepción de las comunidades afectadas, fue un hecho que se trató de un engaño gestado en complicidad con los periodistas del canal. Lo que se puede ver en este análisis de fragmentos de la entrevista es que dentro de la noticia hay un evento inventado o engañoso. Vemos que la noticia como género, o el reportaje noticioso, o su anunciación como entrevista, aparecen como marco que etiqueta

\footnotetext{
Comunicado leído en la radio comunitaria Meridiano 70.
} 
el contenido como real y veraz -es decir, ocurrió- que, junto con la fuente de información, fuente no ficcional consultada, encubren ese evento engañoso de una probabilidad de que sea verdadero. Se trata de una historia falsa descrita como una historia verdadera; pero en el fondo es una historia falsa contada para engañar. ¿Es la introducción de historias falsas y emociones de ira o indignación una manera loable de los medios tradicionales de motivar a la audiencia a participar del juego político de las elecciones?

Tabla 5. Matriz para contraste de contenidos

\begin{tabular}{llc}
\hline \multicolumn{1}{c}{ c } & \multicolumn{1}{c}{2} & 3 \\
\hline \multicolumn{1}{c}{ Propiedades internas } & \multicolumn{1}{c}{ Relaciones contextuales } & Interpretación \\
\hline Expresidentes a la JEP & Polarización: sí y no al acuerdo & "Es una venganza de las FARC" \\
Venezolanización & Socialismo latinoamericano & "Nos vamos a volver como ellos" \\
Impunidad & Víctimas insatisfechas & "No se castiga a los victimarios" \\
\hline
\end{tabular}

Fuente: elaboración propia.

\section{Discusión}

Los periodistas confían la externalización del trabajo emocional a los no periodistas, a los protagonistas de la historia y a otras fuentes, como lo sostiene Wahl-Jorgensen (2013). Esta autora nos ayuda a comprender que, a pesar de su anunciada objetividad, los periodistas están inmersos en una práctica institucionalizada y sistemática de narrar reportajes con emoción; ello significa que la narración periodística, a pesar de su fidelidad al ideal de objetividad, es también profundamente emocional. Si bien lo uno no quita lo otro, en el caso colombiano los periodistas no dejan de perder neutralidad y objetividad al promover de algún modo, el enojo o la ira contra la implementación de los acuerdos de paz, o el supuesto desconocimiento de los resultados del plebiscito, de tal forma que dirigen la ira a un objeto con el que se conecta a una audiencia de más de seis millones de personas.

Aunque la ira es, en primera instancia, una emoción individual, importa políticamente cuando la articulan los colectivos, generalmente hacia un objetivo compartido de abordar una injusticia. (Wahl-Jorgensen, 2018, p. 3)

Estas consideraciones sugieren que, lejos de prescindir del concepto de objetividad, podemos comprender útilmente la emocionalidad como un complemento profundamente constitutivo de las narrativas periodísticas. Es decir, las noticias están emotivamente construidas, hecho significativo desde el punto de vista de la persuasión. Como vimos en la revisión de literatura, varios estudios han demostrado que los sesgos en el procesamiento de la información se produjeron debido a las emociones experimentadas por los espectadores al ver los materiales audiovisuales. La pregunta 
es, entonces, ¿cómo se insertan estas emociones en la narrativa? O mejor aún, ¿qué estimula la emoción en las audiencias? No estará demás responder a la pregunta con una palabra: el engaño.

Las investigaciones de Konijn et al., (2009) dejan ver que el encuadre de un segmento televisado basado en la realidad o basado en la ficción contribuye menos a las atribuciones de valor de la información en comparación con las propias percepciones de los espectadores sobre cuán realista o no es un contenido. Sin embargo, para el caso de la entrevista que se analizó en este artículo, a pesar de ser encuadrada y etiquetada de esta manera por varios paratextos, incluida la introducción que hacen las presentadoras, sus etiquetas contribuyeron menos a valorar la información contenida y más a la emoción representada, que fue estimulada con adjetivos enunciados por los periodistas, pero como citas de lo dicho por el entrevistado, con lo que se preparó el desplazamiento narrativo cuyo destino final es la estimulación emocional de una audiencia que no puede distinguir o distanciarse de la información; más bien queda conectada emocionalmente con la indignación que experimenta el personaje narrador.

Aquí aparece el sesgo emocional. Si bien el encuadre y las instrucciones parecen tener efectos insignificantes en el transporte, es lo que está dentro del encuadramiento lo que interesa: no solo para ver cómo opera la inserción de la emoción como provisiones para el viaje persuasivo sino cómo esta operación de montaje de grandes sintagmas (Metz, 1966) se vuelve un engaño. Cabe aclarar, sin embargo, que persuadir no significa mentir. Retomar el clásico artículo sobre estudios de noticias de Molotch y Lester (1974) puede ayudar para la comprensión de cómo las noticias hacen de sucesos rutinarios grandes acontecimientos, al analizar las finalidades que subyacen a las estrategias de creación de una u otra realidad.

Entre los posibles mediadores del efecto de las narraciones emotivas sobre las creencias se encuentran el enfoque de la atención, la producción de imágenes y la expresión emocional que propicia el traslado narrativo (véanse Green y Brock, 2000), creencias materializadas en un video y una retórica de enojo que convoca la indignación de la audiencia por cuenta del lenguaje audiovisual, pero también por lo creíble que parece el video y porque el mismo entrevistado parece de verdad indignado. Así, observamos que las emociones apuntan a la presencia de cierta preocupación. Frases del entrevistado potencian el estímulo que procuran las imágenes. La relevancia (emocional) existe debido al desplazamiento: nos involucra -hasta cierto punto- en las situaciones, personajes y eventos de un mundo mediado; como espectadores podemos experimentar emociones a través de la empatía, la identificación o el devenir emocionalmente involucrado. 


\section{Resultados}

Respecto al material analizado, y de acuerdo con la teoría discutida en torno a emociones, engaños y distorsión, existe un primer nivel de engaño en el uso inadecuado de etiquetas como paratextos, dado que no esperamos que una noticia del noticiero central sea falsa o incorpore declaraciones falsas, a menos que se anunciara la entrevista a un imitador del candidato.

Un segundo momento de engaño tiene que ver más con la postura y actitud del candidato al compartir un material débilmente informado, o débilmente contextualizado, que con el mismo material, y es que, "primero inconsciente y después conscientemente", como lo diría Hall (1973/1966), el entrevistado intenta ocultar que miente, con lo que la manipulación emocional de un medio noticioso también usa el performance de los cuerpos y no solo la gramática del lenguaje audiovisual.

Sumado a lo anterior, el material evidencia, además de un sesgo por distorsión, la retórica de odio del político entrevistado y el desinterés del medio por el impacto social de sus prácticas que más bien favorece el impacto comercial o publicitario del espacio. La consumación del engaño estaba proyectada para obtener la atención de futuros votantes o copartidarios del candidato, así como para aumentar el índice de audiencia del noticiero e imponer un tema para la agenda política y mediática de la semana. Este último factor deja ver que el sesgo emocional procurado por el medio no es solo partidista, sin querer decir que la artimaña mediática no quería favorecer al candidato; se trató principalmente de un sesgo por distorsión de la información que favorecía al noticiero, a los comerciantes que pautaron en el espacio y al canal que legitimó su dominación del índice de audiencia en ese horario.

Una encuesta realizada por Datexco (WRadio, 2017) para los medios de comunicación masiva W Radio y El Tiempo, varios días después de difundida la entrevista en cuestión y que se centraba en la figura de Vargas Lleras, estableció que el 68,3 \% de los encuestados no votaría por dicho aspirante en las elecciones a presidencia en el 2018. A la pregunta "¿Usted le cree o no le cree a Germán Vargas Lleras?", 65,9 \% respondió de forma negativa, lo que comprueba que el sesgo solo favoreció al medio. ¿Mentir para ganar dinero?

\section{Conclusiones}

Vale decir en este punto que las conclusiones iniciales del presente estudio de caso son observaciones culturales que están limitadas al área y periodo estudiados. Así entonces, una de las conclusiones preliminares radica en que el sesgo emocional que procuran los medios informativos tradicionales no es solo de carácter partidista; también está en juego el índice de audiencia. 
El engaño en los medios de información tradicionales se puede clasificar por niveles, en el primero de los cuales encontramos el uso inadecuado de etiquetas como paratextos. Sin embargo, fue posible comprobar que la manipulación emocional de un medio noticioso también usa el performance de los cuerpos de presentadores y entrevistados, y no solo la gramática del lenguaje audiovisual. Pero más aún, y además del sesgo por distorsión y la retórica de odio del político entrevistado, se hizo evidente el desinterés del medio por el impacto social de sus prácticas para favorecer el impacto comercial o publicitario del espacio. Por último, se pudo identificar que el sesgo emocional con el que el medio construye las noticias no es solo partidista, sin significar esto que la artimaña mediática no quería favorecer a un candidato o propuesta política.

Además de despejar la variable del origen histórico de las fake news, con el desarrollo del presente artículo se identificó el rol de los medios de información tradicionales: por favorecer el mercado publicitario y réditos del índice de audiencia, crean las condiciones para el flujo de noticias falsas; esto es, noticias descontextualizadas, sin verificación de fuentes y con frases engañosas, que dejan ver los sesgos por distorsión, emocional y partidista, sobre los que el medio informativo configura un engaño.

\section{Referencias}

Allcott, H., y Gentzkow, M. (2017). Redes sociales y noticias falsas en las elecciones de 2016. Journal of Economic Perspectives, 31(2), 211-36.

Alvermann, D. (2017). Social Media Texts and Critical Inquiry in a Post-Factual Era. Journal of Adolescent y Adult Literacy, 61(3), 335-338. https://doi.org/10.1002/jaal.694.

Appel, M., y Maleckar, B. (2012). The Influence of Paratext on Narrative Persuasion: Fact, Fiction, or Fake? Human Communication Research, 38(4), 459-484.

Appel, M., y Richter, T. (2010). Transportation and Need for Affect in Narrative Persuasion:siepiA Mediated Moderation Model. Media Psychology, 13, 101-135.

Balcázar, P., González, N., y Gurrola, M. (2010). Investigación cualitativa. Universidad Autónoma del Estado de México.

Beuchot, M. (1997). Argumentación y Falacias en Aristóteles. Tópicos, 12, 9-18.

Bolton D., y Yaxley, J. (2017). Fake news and clickbait - natural enemies of evidence-based medicine. BJU International, 119(5), 8-9.

Caramon, M., y Martínez-Martínez, J. (2004). La investigación de la enseñanza a partir del estudio de caso y el trabajo de caso. En M. Murueta, Alternativas metodológicas para la investigación educativa. Centro de Estudios Superiores en Educación.

Chen, A. (2017, septiembre 4). The Fake-News Fallacy. The New Yorker. Recuperado de: https://www. newyorker.com/magazine/2017/09/04/the-fake-news-fallacy?utm_content=bufferfc8edyutm_ medium $=$ social\&utm_source $=$ twitter.com\&utm_campaign $=$ buffer. 
Editorial Santillana (2005). Diccionario de las ciencias de la educación. Santillana.

El Heraldo y Uninorte. (2017, marzo 20). Las dualidades de la justicia transicional. El Heraldo. Recuperado de: https://www.elheraldo.co/politica/las-dualidades-de-la-justiciatransicional-338666

Enguix, S. (2017). Impacto político e informativo de las redes sociales: esferas de actuación y comparación con los medios. Anàlisi. Quaderns de Comunicació i Cultura, 56, 71 -85. http://dx.doi. org/10.5565/rev/analisi.3090

Gentzkow, M., Shapiro, J., y Stone, D. (2014). Media Bias in the Marketplace: Theory. En S. Anderson, D. Strömberg y J. Waldfogel (Eds.) Handbook of Media Economics (vol. 1, pp. ).. Amsterdam: North-Holland.

Gobierno Nacional y Farc-EP (2016, noviembre 24). Acuerdo final para la terminación del conflicto y la construcción de una paz estable y duradera. Alto Comisionado para la Paz. Recuperado de http://www.altocomisionadoparalapaz.gov.co/procesos-y-conversaciones/Documentos\%20 compartidos/24-11-2016NuevoAcuerdoFinal.pdf

Gómez, A., y Agudelo López, A. (2016). Crisis democrática en América latina y alternativas de participación política juvenil en Medellín (COL). Realis, 6(2), 22-35.

Green, M., y Brock, T. (2000). The role of transportation in the persuasiveness of public narratives. Journal of Personality and Social Psychology, 79, 701-721. https://doi.org/10.1037/0022 3514.79.5.701

Green, M., y Donahue, J. (2009). Simulated Worlds: Transportation into Narratives. En K. Markman, W. Klein y J. Suhr (eds.), Handbook of imagination and mental simulation (pp. 241-256). Psychology Press.

Green, M., y Brock, T. (2000). The Role of Transportation in the Persuasiveness of Public Narratives. Journal of Personality and Social Psychology, 79(5), 701-721.

Hall, E. (1966). The Hidden Dimension. Doubleday.

Human Rights Watch (2017). Philippines: Duterte's first year a human rights calamity. Recuperado de https://www.hrw.org/news/2017/06/28/philippines-dutertes-first-year-human-rights-calamity

Humanes, M. (2001). El encuadre mediático de la realidad social. Un análisis de los contenidos informativos en televisión. Zer Revista: Estudios de comunicación, 6(11), 386. Recuperado de https:// www.ehu.eus/ojs/index.php/Zer/article/view/6072/5754

Jociles, M. (2005). El análisis del discurso: de cómo utilizar desde la antropología social la propuesta analítica de Jesús Ibáñez. Avá. Revista de Antropología, 7, 1-25.

Konijn, E., Van der Molen, W., y Van Nes, S. (2009). Emotions Bias Perceptions of Realism in Audiovisual Media: Why We May Take Fiction for Real. Discourse Processes, 46(4), 309-340. https:// doi.org/10.1080/01638530902728546

Labiste, M. (2017) Media Reviews. Asian Politics y Policy, 9(4), 697-715. https://doi.org/10.1111/ aspp. 12348

La República (2016, octubre 6). "Estábamos buscando que la gente saliera a votar verraca": Juan C. Vélez. El Colombiano. Recuperado de https://www.elcolombiano.com/colombia/acuerdos- 
de-gobierno-y-farc/entrevista-a-juan-carlos-velez-sobre-la-estrategia-de-la-campana-del-noen-el-plebiscito-CE5 116400

Maio, G. y Esses, V. (2001). The need for affect: individual differences in the motivation to approach or avoid emotions. Journal of Personality, (69), 585-615.

Malagón, S. (2016, octubre, 30). El debate sobre género que aún hay que dar. Semana. Recuperado de: https://www.semana.com/nacion/articulo/el-debate-sobre-genero-en-colombia/502738

Meridiano 70 (2017, octubre 18). German Vargas Lleras estigmatiza al pueblo de Saravena: Diego Vera. Meridiano 70. Recuperado de: http://meridiano70.co/german-vargas-lleras-estigmatizaal-pueblo-de-saravena-diego-vera/.

Metz, C. (1966). La grande syntagmatique du film narratif. Communications, 8, 120-124.

Molero de Cabeza, L. (2003). El enfoque semántico-pragmático en el análisis del discurso. Visión teórica actual. Revista Lingua Americana, 12, 5-28.

Molotch, H., y Lester, M. (1974) Las noticias como conducta intencionada: sobre el uso estratégico de los acontecimientos rutinarios, los accidentes y los escándalos. American Sociological Review, 39, 285-305.

Muñoz, P. (2017). Medios de comunicación y posverdad: Análisis de las noticias falsas en elecciones presidenciales de EE. UU. de 2016 (tesis de maestría). Departamento de Medios, Comunicación y Cultura, Universidad Autónoma de Barcelona.

Noticias Caracol (2017, octubre 17). "No creo que haya que hacer trizas los acuerdos de paz": Germán Vargas Lleras. Noticias Caracol. Recuperado de https:/www.youtube.com/ watch?v=8Fuaww $14 \mathrm{UbI}$

Rappler (s. f.). Fact Check. Rappler. Recuperado de: https://www.rappler.com/newsbreak/fact-check

Ressa, M. (2016, octubre 3). Propaganda War: Weaponizing the Internet. Rappler. Recuperado de http://www.rappler.com/nation/148007-propaganda-war-weaponizing-internet

Reyes, T. (1999). Los métodos cualitativos de investigación. Universidad de Buenos Aires. Recuperado de http://jbposgrado.org/icuali/Estudio\%20de\%20caso\%20y\%20grupo\%20focal.pdf

Romano, V. (2011). La intoxicación lingüística, el uso perverso de la lengua. Correo del Orinoco.sepe.

Romano, V. (2012). La violencia mediática; el secuestro del conocimiento. Correo del Orinoco.sép:

Semana.com (2018, julio 12). Gustavo Petro pasó a Germán Vargas Lleras. Semana.com. Recuperado de https://www.semana.com/nacion/articulo/german-vargas-lleras-y-gustavo-petro-granencuesta-invamer/549747

Wahl-Jorgensen, K. (2013). The Strategic Ritual of Emotionality: A Case Study of Pulitzer Prizewinning Articles. Journalism, 14(1), 129-145. DOI: https://doi.org/10.1177/1464884912448918

Wahl-Jorgensen, K. (2018). Media coverage of shifting emotional regimes: Donald Trump's angry populism. Media, Culture \& Society, 40(5), 766-778. https://doi.org/10.1177/0163443718772190

Welles, O. (2015). Frases de Orson Welles. Recuperado de https://citas.in/autores/orson-welles/

WRadio (2017). Opinómetro. WRadio. Recuperado de https://www.wradio.com.co/ docs/201710193b8a50c6.pdf 